\title{
Errata to: Diversity and Evolution of Butterfly Wing Patterns
}

\author{
Toshio Sekimura and H. Frederik Nijhout
}

\section{Errata to: \\ T. Sekimura, H.F. Nijhout (eds.), Diversity and \\ Evolution of Butterfly Wing Patterns, DOI 10.1007/978-981-10-4956-9}

In Chapter 3: Camouflage Variations on a Theme of the Nymphalid Ground Plan Takao K. Suzuki

The original version of this chapter was inadvertently published without figure 3.4. The figure is inserted in the current version.

In Chapter 11: Chemical Ecology of Poisonous Butterflies: Model or Mimic? A Paradox of Sexual Dimorphisms in Müllerian Mimicry

Ritsuo Nishida

The original version of this chapter was inadvertently published without figure 11.5. The figure is inserted in the current version.

\footnotetext{
The online version of the original chapter can be found under https://doi.org/10.1007/978-981-10-4956-9_3

https://doi.org/10.1007/978-981-10-4956-9_11

https://doi.org/10.1007/978-981-10-4956-9_17

https://doi.org/10.1007/978-981-10-4956-9
} 
In Chapter 17: Molecular Mechanisms Underlying Color Vision and Color Formation in Dragonflies

Ryo Futahashi

The original version of this chapter was inadvertently published without figure 17.7. The figure is inserted in the current version. 